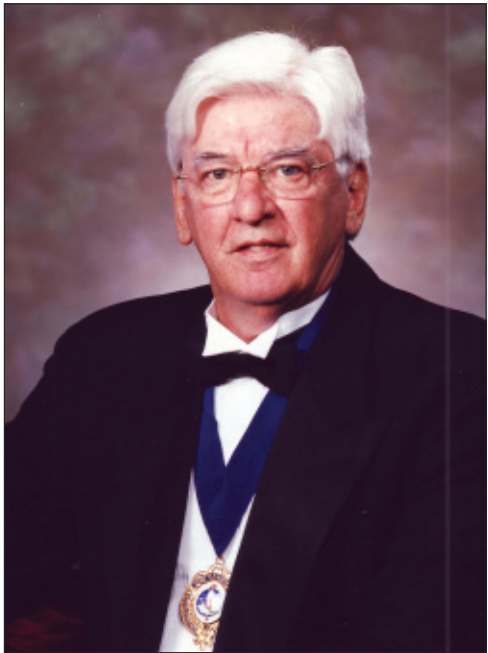

Dr. Normand Sullivan

CUAJ honours its members and friends who have passed away. We invite colleagues of the deceased to submit brief remembrances. Please limit your notice to 200 words. Send your notice to journal@cua.org or fax it to 514 875-0205.

\section{Dr. Normand Sullivan}

Dr. Normand Sullivan died at his home in Ste-Anne de Sorel on Monday, Nov. 10, 2008, at the age of 67.

The Canadian Urological Association (CUA), the Quebec Urological Association (QUA) and the Northeastern Section of the American Urological Association (NS-AUA) lost a hard-working friend and leader.

Normand left behind his wife, Marjorie, and their 3 children, Kimberley, Michael and Paul. He also left behind a legacy; because of his efforts, the CUA, QUA and NS-AUA have the financial stability and ability to provide young academic urologists with scholarships to start their scientific urology careers.

He organized many national and international meetings for the QUA and was recognized by the association with the Jean Charbonneau Prize.

I met Normand while he was president of the QUA. We became good friends and decided to work together to raise funds for the NS-AUA. We partnered with industry and provided money for better meetings. We received funding from Searle Canada and USA to start the Research and Education Fund. Dr. Anthony Passaretti and Dr. Datta Wagle joined us on the development committee and remarkable results followed. Twenty-two scholarships have been given to promising young academic urologists. The fund is now the NS-AUA Scholarship Foundation. Normand received the Distinguished Service Award in 1997 from the NS-AUA; only 8 such awards have been given over the section's 60-year history.

In 1992, Normand was elected treasurer of the CUA Scholarship Foundation (CUASF). The Foundation was started by Dr. Kenneth MacKinnon and had given 2-3 scholarships annually. During Normand's tenure, 5-6 scholarships were given each year and the principle in the foundation grew to $\$ 1.5$ million. This provided the CUASF security, enabling it to award scholarships for years to come. He was also president of the CUA 1996/97. He received the CUA Lifetime Achievement Award in 2003 in recognition of his remarkable efforts.

Normand was easy to work with. His honesty and generous personality impressed those with whom he negotiated. He always did exactly what he said he would do. He wanted to make a difference and that's what he did. Scholarships have elevated the urology specialty both in Canada and in the United States. We all miss him as one of our best friends.

Well done, Dr. Normand Sullivan.

Dr. Jack Sales, MD, FRCSC

London, Ont. 